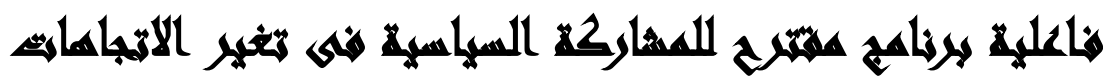

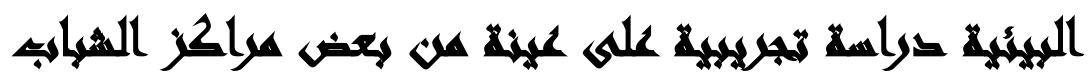 \\ بالجاهرة}

\section{[1}

محمود السيد أبو النيل (')- إجلال اسماعيل حلمى(')- ثروت أبو العباس عثمان(؟)

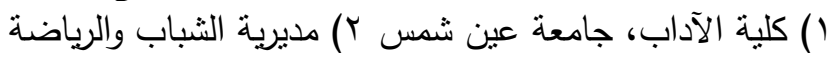

\section{المستخليه}

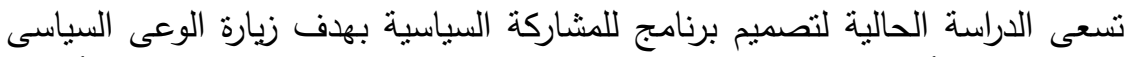

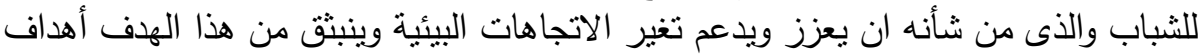

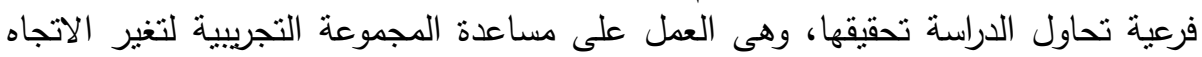

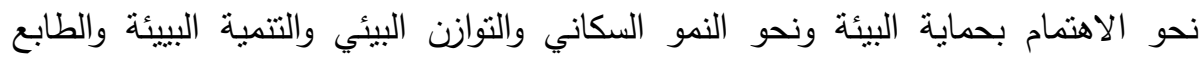
الجمالي للبيئيه التعرف على الفروق بين المجموعتين التجريبيتين باختلاف العينات ) عشوائية

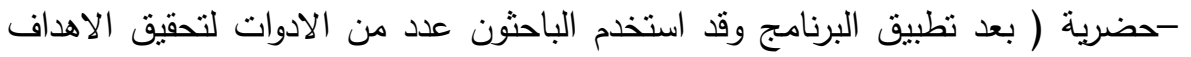

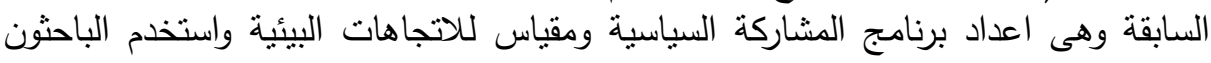

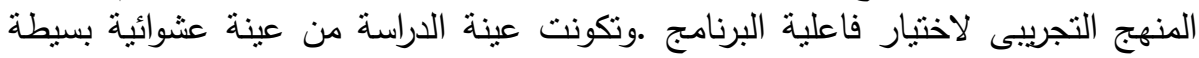

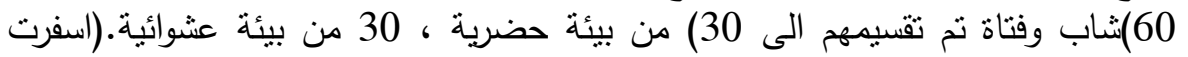

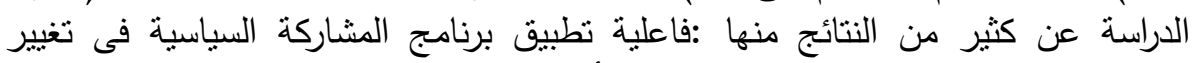

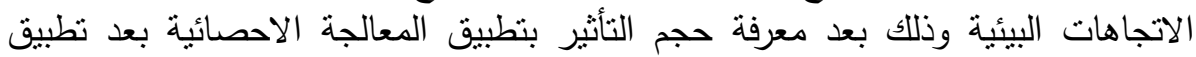

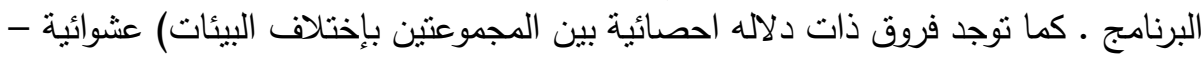

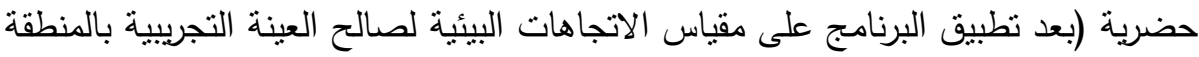

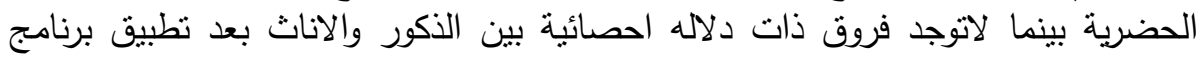

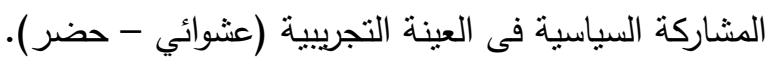




\section{xaradl}

أصبحت قضية الاهتمام بالبيئة أحد القضايا الهامة التي فرضت نفسها على الناس جميعا من مختلف الأجناس والطبقات والأديان وأفلحت في فرض نفسها بشكل قوي منذ بداية

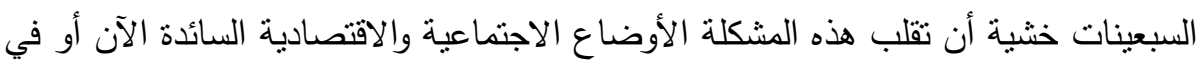
المستقبل القريب أو البعيد ولذلك شهدت مشكلة البيئة زيادة كبيرة في اهتمام العلماء المخططين والسياسيين رجال الاقتصاد وعلماء الاجتماع وعلماء البيئة البيولوجية انعكس في كثرة الكتابات لتبينه كل البشر للأخطار المحدقة بالبيئة الطبيعية وطريقة الحفاظ عليها بتحقيق التوازن الأيكلوجي لكل عناصر البيئة كما تجلي في اهتماما لمنظمات الدولية والعلمية بعقد مئات المؤتمرات والندوات التي تعالج فيها مشكلة البيئة بوجه عام واثر مشكلة البيئة على التقدم الحضاري بالإضافة إلى اهتمام الدول المتقدمة والنامية بإنشاء وزارات وهيئات وأجهزة لشئون

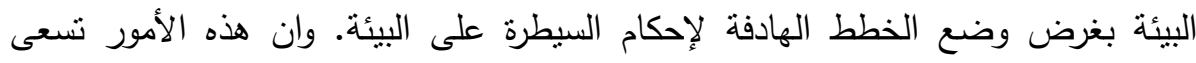

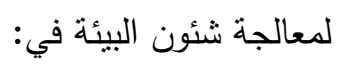
• الاعتراف بموقف الإنسان المعادي للطبيعة وعدم إدراكه للحدودية مصادر الثروة الطبيعية وزيادة استهلاكه لها نتيجة المشكلة السكانية

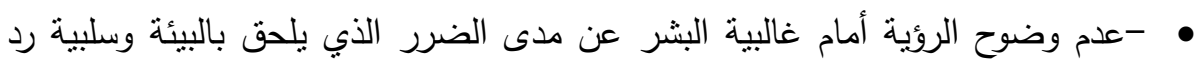
الفعل والاهتمام • ضرورة معرفة الإنسان لمواطن الخلل في العلاقة بين الإنسان والبيئة وان بداية العلاج تؤكد أهمية الناحية السلوكية بين الإنسان المستفيد من البيئة والسبب الرئيسي في تلويثنها

$$
\text { عبد الفتاح غنيمة، (2001) }
$$

لما كانت الاتجاهات تعتبر من أهم مكونات الخبرة التي تحدد مدي قدرة الفرد على

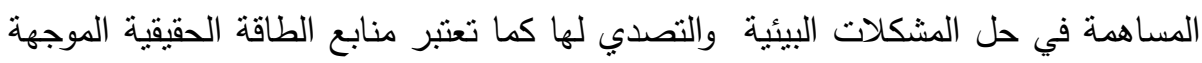

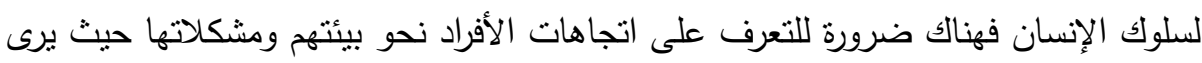
بعض المربون أن الحل الجذري للأزمة البيئية الراهنة يتطلب تغيرا كبيرا في اتجاهات الإنسان 
إزاء بيئته بل أن بضعهم يرى أن الثورة البيئية التي نحن فيها في حاجة إليها إنما هي ثورة الاتجاهات.

والاتجاهات هي استعدادات تكتسب نتيجة لما يمر به الفرد من خبرات ويتميز الاتجاه بأنه قد يكون قابلا للانتقال من شخص لآخر ويكون لمصلحة الجماعة على حساب مصلحة الأفراد ويعني ذلك أنه ليس مقصورا على الأفراد بل بمنا أيضا إلى الجماعات. المجال السياسي أحد المجالات الهامة لتتمية وتطوير المجتمع والبيئة فالمشاركة السياسية تتمي الوعي لدى الجماهير وتناعد على زيادة خبراتهم وثقافتهم السياسية وتجعلهم ولهيه

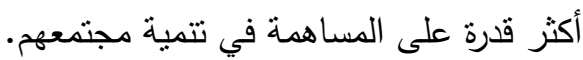
حيث تعتبر المشاركة السياسية مظهرا من مظاهر نضج الوعي السياسي لدي الجماهير فهي تلعب دورا حيويا في ديناميات بناء الأمة كما أنها تمثل عملية آلية سياسية لها تأثيرها الفعال في تطوير وبلورة أنماط جديدة من الولاء السياسي منِ مهارات المشاركة السياسية بأن

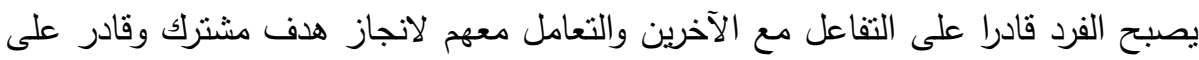

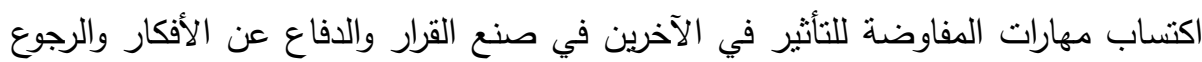

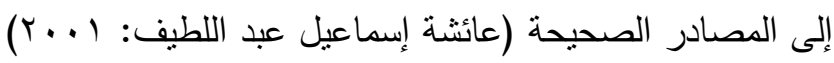
أن هناك قدر من الارتباط بين المشاركة السياسية والمشاركة في المجالات غير إناعل

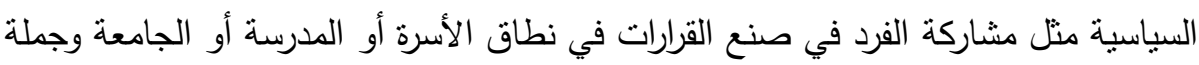

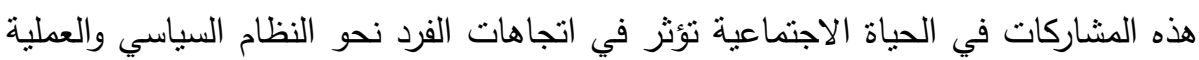

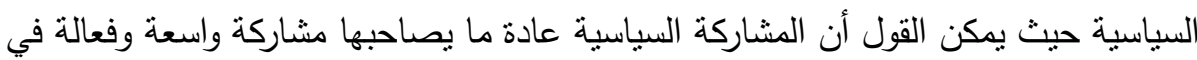

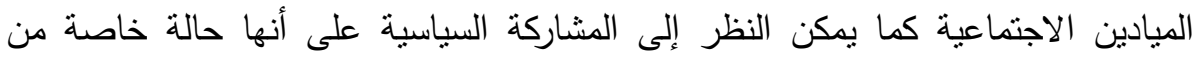
المشاركة العامة في الحياة الاجتماعية نؤثر في الأنشطة المجتمعية. الثباب كثروة بشرية في مصر تمثل أكثر من 60 من مجموع السكان فهو عنصر الهر فعال

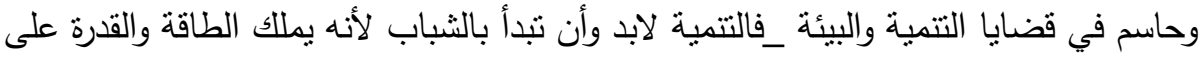
العطاء وتكاد المشاركة أن تكون هالمدخل الحقيقي لتعبئة طاقات الأجيال الصاعدة وتجديد الدماء في شرايين النظام السياسي والاجتماعي للأمة والمساهمة في حركة التتمية المتواصلة. لكادئه

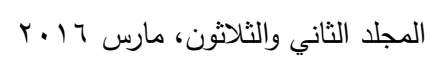


ومن هنا كان الاهتمام بالقيام بدراسة حول فاعلية برنامج للمشاركة السياسية في تغيير

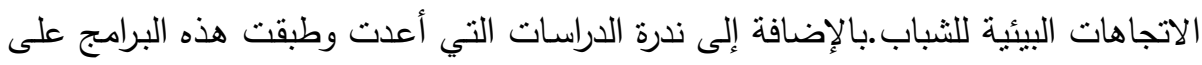

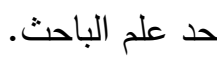

\section{xan}

مع تتامى الاهتمامات البيئية يرى بعض المربون أن الحل الجذرى للازمة البيئية الراهنة

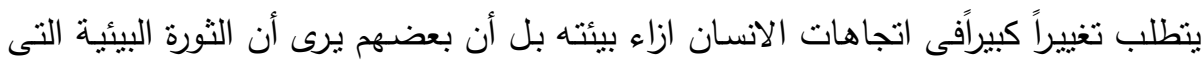

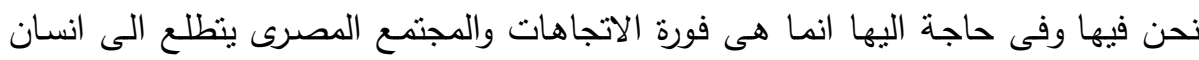

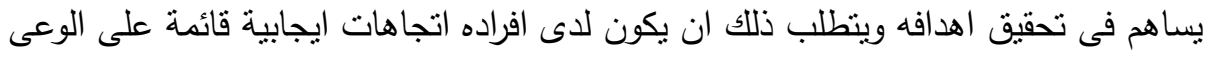

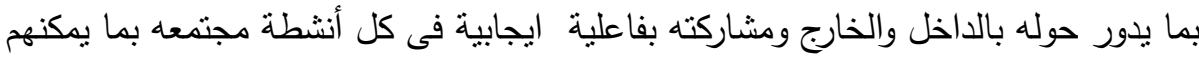

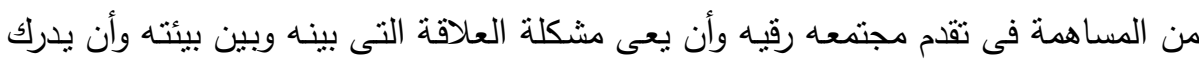
بناء نسق القيم البيئية تجاه قضايا البيئة ومشكلاتها تؤكد نتائج بعض الدراسات أن المجال السياسى أحد المجالات الهامة لتنمية وتطوير المجتمع والبيئة فالمشاركة السياسية تتمى الوعى لدى الجماهير وتساعد على زيادة خبراتهز وتقافاتهم السياسية وتجعلهم اكثر قدرة على المساهمة فى تتمية مجتمعهم كدراسة محمد السيد عبد الفتاح (2003) ودراسة صفاء محمد على (2005) دراسة paske,josh,2006 دراسة سعاد حسنى(2007)

تؤكد نتائج بعض الدراسات الى ضعف الدور الذى تقوم به مؤسسات التنشئة السياسية

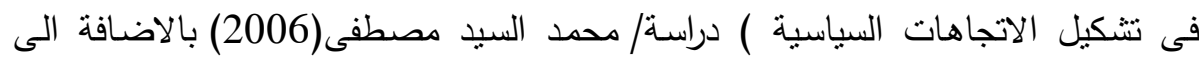

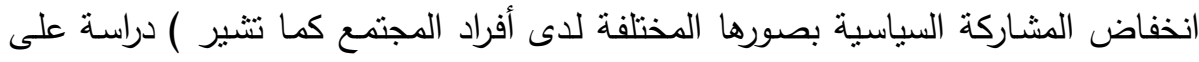

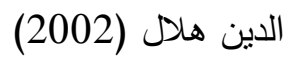
وتؤكد العديد من الدرلسات الحاجة الى عمل برامج تدريبية سياسية تساهم فى نمو

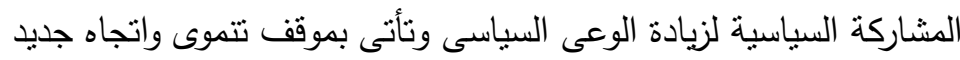




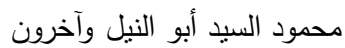

(Milbrn2000)، $\quad$ (

(Reimders,Einz,others,2005)،(Richardson,Wendyklandi,2004)

دراسة سامية عطا2007

وعلى ضوء ماسبق تتمثل مشكلة الدراسة فى الحاجة الى تصميم برنامج للمشاركة

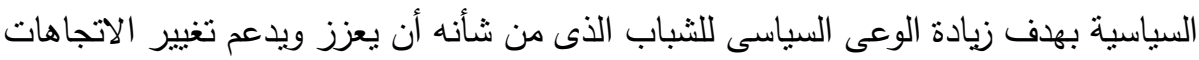
البيئية والدراسة الحالية تربط بين متغيرين الاول: برنامج المشاركة السياسية الثانى: تغير الاتجاهات البيئية

\section{أسئلة الكراسة}

ما مدى فاعلية برنامج مقدم للمشاركة السياسية فى تغير الاتجاهات البيئية؟ ومن التساؤل الرئيسى الاسئلة الفرعية الاتية:

1-ما هى صورة برنامج المشاركة السياسية لتغير الاتجاهات البيئية؟ ץ-ما هى فاعلية البرنامج المقترح على تغير الاتجاهات البيئية (فى منطقىى عشوائية ومنطقة حضرية)؛

ب-هل توحد الفروق بين الهجوعتين باختلاف البيئات ) عشوائية-حضرية (بعد تطبيق البرنامج?

\section{أهداهئ الكراسة}

1-زيادة الوعى السياسي الذى من شأنه أن يعزز ويدعم تغيير الاتجاهات البيئية من خلال تطبيق برنامج المشاركة السياسية. r-التعرف على الفروف بين المجموعتين التجربتين باختلاف البيئات (العشوائية - الحضرية) بعد تطبيق البرنامج. 


\section{أهمية التراسما}

أولاً: الأهمية النظرية:

1-يزداد الاهتمام بالبيئة لان البيئة المصرية تتعرض للعديد من المشكلات البيئية مثل

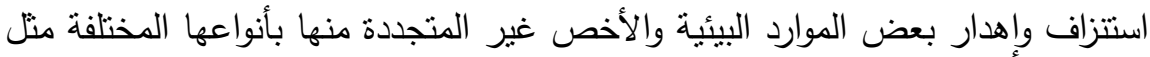
البترول ومشكلة التلوث وانتشار الأنماط السلوكية السلبية التي تضر بالبيئة. r-وتؤكد معظم الدراسات البيئية على أهمية العنصر البشري في حماية البيئية والمحافظة

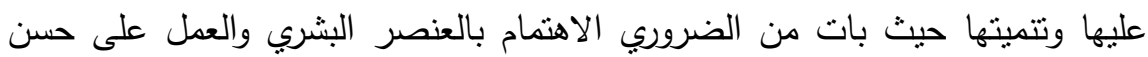
تتميته وإعداده بشكل يتحقق من خلاله قدرة الإنسان في المحافظة على البيئة.

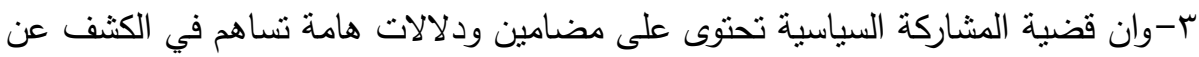

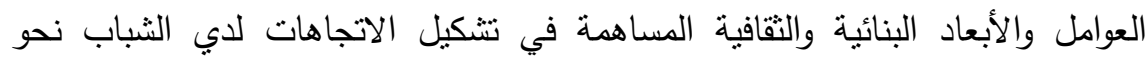

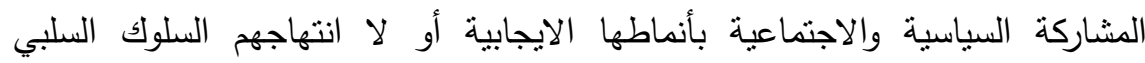
واللامبالاة والعزلة السياسية في المجتمع. ع-تقوية وتدعيم المشاركة السياسية لدي الثباب يعد موردا أساسيا لإمداد الأجهزة السياسية

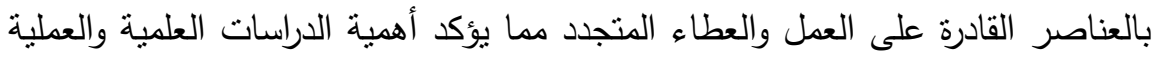

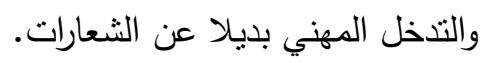
ه- أكدت معظم الدراسات على أهمية المشاركة بصفة عامة والمشاركة السياسية بصفة خاصة وذللك لارتباطها بالتتمية الاجتماعية. يسعي البحث الحالي إلى توضيح أهمية المشاركة السياسية في زيادة الوعي السياسي الذي من شأنه أن يعزز ويدعم تغير الاتجاهات البيئية للشباب. ثانياً: الأهمية التطبيقية: 1-تصميم وتوفير برنامج للمشاركة السياسية لتغيير الاتجاهات البيئية للشباب. r-الاستفادة من نتائج الدراسة في تطبيق البرنامج كبرامج وقائية موجهه للجميع والبيئة لمعالجة تغير الاتجاهات البيئية. 
r-أنها تتمشي مع الدعوة المطالبة من قبل بعض الباحثين بضرورة انتقال البحوث النفسية والاجنماعية والتربوية البيئية من مرحلة الوصف والبحث عن العوامل والأسباب المرتبطة لمرحلة التنخل المباشر في الظاهرة. التعريف الاجرائى لمفاهيم الدراسة:

\section{أولا: مفهوم الفاعلية(Effectiveness)}

الباحث يقصد بالفاعلية في هذه الدراسة ) قدرة هذا البرنامج ومحتوياته على تتمية قدرة

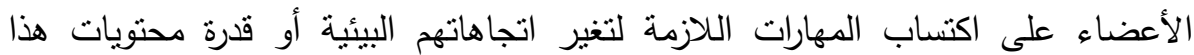
البرنامج على تحقيق نتائج مرغوبة في الممارسة الميدانية الفعلية ثانياً: مفهوم البرنامجج: تعريف /جائسي: مجموعة من الأنشطة وخطط العمل المختلفة التي يمارسها أعضاء الجماعة التجريبية سواء كانت هذه الأنشطة والخطط اجتماعية أو نقافية أو ترويحية أو دينية أو سياسية أو بيئية تتفق مع قدرات ورغبات أعضاء الجماعة وامكانيات المؤسسة. مفهوم المشاركة السياسية

يتبنى الباحث التعريف التالى: المشاركة السياسية:عملية اجتماعية سياسية طوعية ورسمية تتضمن سلوكا منظما مشروعا متواصلا يعبر عن اتجاه عقلاني رشيد ينم عن إدراك عميق لنقئه

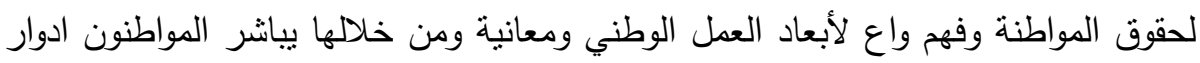

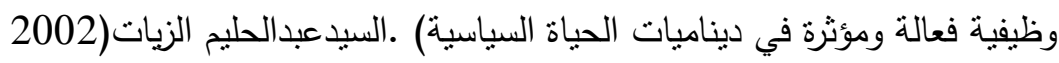


برنامج للمشاركة السياسية: الهدف العام لبرنامج المشاركة السياسية زيادة الوعي السياسي

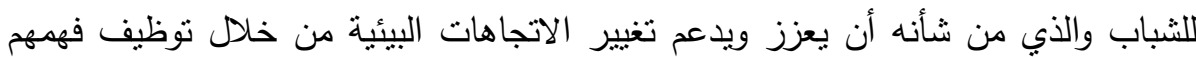
وطاقاتهم وقدراتهم بالمجال المكاني للاراسة بممارسة مجموعة من النشاطات ويتحقق هذات الهدف من خلال مجموعة من الاليات كالتالي:

المحاضرات والندوات والمناقثات لزيادة معدل النمو الثقافي لعضو الجماعة بالجوانب

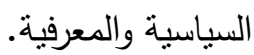

تفعيل المناقثة الجماعية والتي من خلالها ينم اكتساب أفكار جديدة لدي المبحوث يسنطيع من خلالها بناء اتجاهات نحو الأمور السياسية والاهتمام بهاء ولهابه ممارسة عضو الجماعة للأنشطة والمتطلبات السياسية) برلمان الطلائع -برلمان الثباب ...الخ النماب

العمل التطوعى لزيادة فاعلية المشاركة وتحمل المسئولية لاي الأعضاء على اعتبار أن

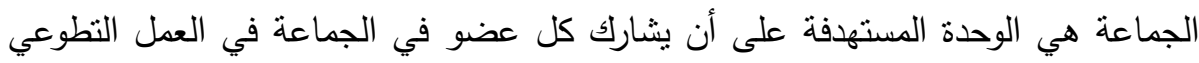
ويتعلم من خلال ذلك كيف يواصل تحمل المسئولية. إحساس عضو الجماعة بمكانته بالعمل على تتمية معارفه السياسية (الاهتمام بالإخبار السياسية ومناقشته الأمور السياسية).

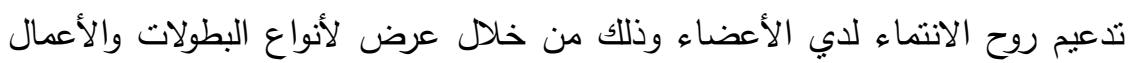
الفدائية والقيام بمعسكرات بيئية لخدمة مجتمعهم المحلي سواء داخل المؤسسة أو خارجها. إتاحة الفرصة لأعضاء الجماعة للعمل التطوعي ولتدعيم اتصالهم بالمجتمع الخارجي عن طريق الاثتراك في بعض المشروعات الجماعية.

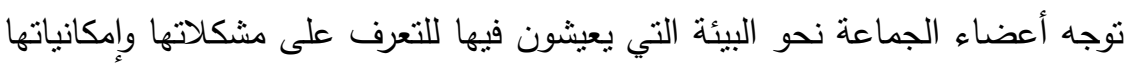

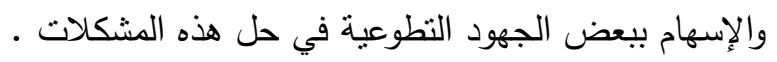

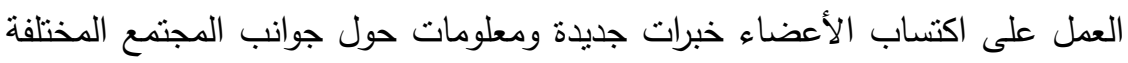

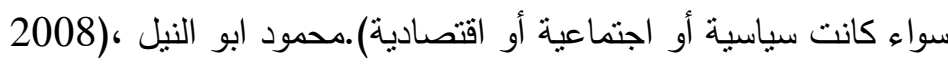


مفهوم الاتجاهات البيئية: هو محصلة المفاهيم والافكار والمعلومات البيئية لدى الفرد التى اكتشفها وتعلمها بالوسائل المختلفة وترسخت فى وجدانه وينعكس على مشاعرة وانفعالاته

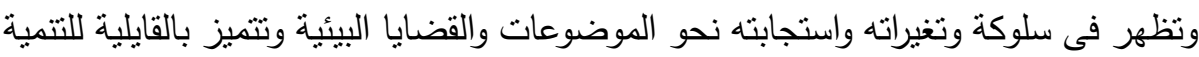

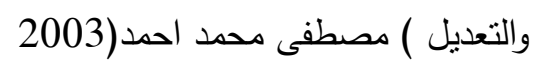

\section{إجراعاهي القراسلا}

الاجراءات التى اتبعها الباحث فى الدراسة الحالية ما يلى: اولا عينه الدراسة: تكونت عينة الدراسة من:

- عينة عشوائية بسيطة تقدر بحوالى الى (30) شاب وفتاه تم تقسيمه الى مجموعنين احداهما تجريبية والاخرى ضابطة كل مجموعة (15) من اعضاء مركز شباب الثرفا المرج ) منطقة عشوائية ( للمرحلة السنية من 17 - 16 سنة. - عينة عشوائية بسيطة تقدر بحوالى (30) شاب وفتاه نم تقسيهم الى مجموعتين احداهما تجريبية والاخرى ضابطة كل مجموعة (15) من اعضاء مركز شباب حلمية الزينو )

$$
\text { منطقة حضرية ( للمرحلة السنية من } 17 \text { - } 16 \text { سنة. }
$$

المجال المكانى مركز شباب حلية الزينون بالقاهرة منطقة حضرية. المجال المكانى مركز شباب الشرفا منطقة عشوائية. المجال الزمانى هى فترة تطبيق البرنامج واجراء التجربة الميدانية استغرقت 3 أنشر من من 31/12/2015. 1/10/2015

$$
\text { الوسائل الإحصائية المستخدمة: لماحئ }
$$

تم تفريغ البيانات عن طريق البرنامج الإحصائي المعروف برنامج الحزم الإحصائية

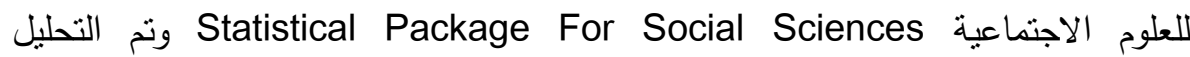
، SPSS V. الإحصائي باستخدام الحاسب الآلي من خلال برنامج الحزم الإحصائية وتعد هذه الخطوة - تفريغ البيانات -خطوة تمهيدية لتبويب البيانات، ومن خلاله نم اختبار فروض الدراسة باستخدام الأساليب الإحصائية الآتية:

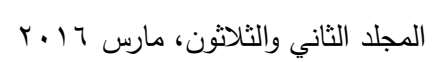




$$
\begin{aligned}
& \text { اختبار" ت T-test "لحساب صدق التمييز وإثبات صحة فروض الدراسة. } \\
& \text { المتوسطات والإنحراف المعياري. } \\
& \text { معادلة إيتا تربيع لحساب حجم تأثثر البرنامج. } \\
& \text { ثانياً أدوات الدراسةة: }
\end{aligned}
$$

1-البرنامج للمشاركة السياسية: من اعداد الباحث يحتوى على مجموعة منتوعة ومتعددة من الانشطة ) نقافى - سياسى - رياضى - فنى -دينى -المشاركة فى الانشطة وجمعيات

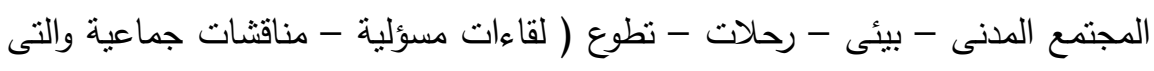
تهدف فى تحملها الى رفع الوعى السياسى الذى من شانة ان ويدعم تغير الاتجاهات

\section{r - ب - مقياس الاتجاهات البيئية:}

تحت الاستعانة بمقياس الاتجاهات البيئية ) مصطفى محمد احمد (2003 بعد ان ادخل علية بعض التعديلات من حيث الاضافة والحزف واعادة الصياغة لبعض المفردات لتتاسب التبان

$$
\text { موضوع الدراسة الحالية. }
$$

وبهذف المقياس الى قياس الاتجاهات البيئية لدى عينة الدراسة ) مجموعة الدراسة ( والتحقيق من فاعلية تطبيق برنامج المشاركة السياسية بعد تطبيق البرنامج على العينة

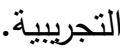

وكانت ابعاد المقياس تمثل الاتجاه نحو (حماية البيئة - النحو التالى التوازن البيئيى -

$$
\begin{aligned}
& \text { التتمية البيئية - المعتقدات البيئية - الطابع الجماعى للبيئة). }
\end{aligned}
$$

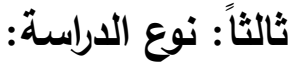

دراسة تجريبية لاختيار فاعلية برنامج المشاركة السياسية فى تغير الاتجاهات البيئية.

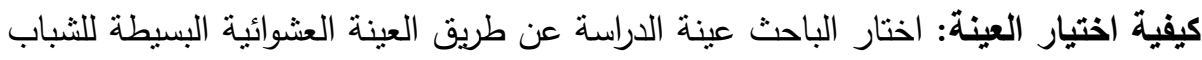
مجتمع البحث ( فى كلا من المنطقة العشوائية ) مركز شباب الثرفا ( والمنطقة الحضرية ) لبنه مركز شباب حلمية الزيتون

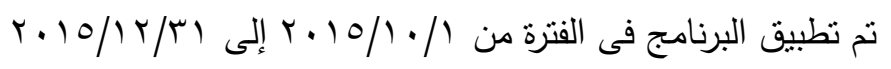




\section{أهم النتائج العامة التى توصلت اليها الدراسة:}

- فاعلية تطبيق برنامج المشاركة السياسية فى تغير الاتجاهات البيأية.

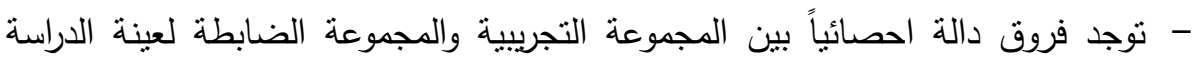
العشوائي بعد تطبيق البرنامج بمقياس الاتجاهات البيئية لصالح العينة التجربية.

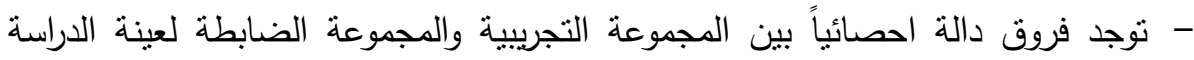
الحضر بعد تطبيق برنامج المشاركة السياسية بمقياس الاتجاهات البيئية لصالح الفئة

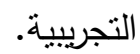
- توجد فروق ذات دلالة احصائية بين العينة) عشوائى - حضرى (باختلاف العينات لصالح

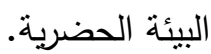
- لا توجد فروق ذات دلالة احصائية بين الذكور والاناث بعد تطبيق برنامج المشاركة

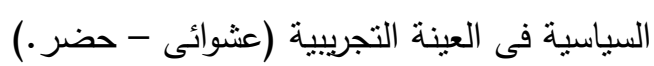

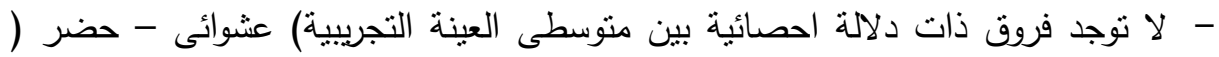
لمتغير المؤهل للوالدين. - يوجد حجم تأثثر لنطبيق برنامج المشاركة السياسية على العينة التجريبية (عشوائى حضرى) 
جدول رقم(1): اختبار ت T-Test (لتوضيح الفروق بين التطبيق القبلي والبعدي للمجموعة

\begin{tabular}{|c|c|c|c|c|c|c|}
\hline & & & & & ( حضر ) & \\
\hline التَأثُر & المعنوية & قيمة ت & الأمعياري & المتوسط & المجموعة & أبعاد المقياس \\
\hline & & & 2.75 & 24.13 & قبلي & \\
\hline 0.969 & 0.001 & 29.554 & 3.87 & 60.33 & بعدي & حمايه البيئه \\
\hline & & & 3.74 & 22.67 & قبلي & \\
\hline 0.944 & 0.001 & 21.739 & 4.45 & 55.27 & بعدى & النمو السكاني \\
\hline 0 087 & $0 \Omega 01$ & 30521 & 2.62 & 22.00 & قبلي & \\
\hline 0.982 & 0.001 & 39.531 & 1.91 & 55.07 & بعدي & اللوارن البيي \\
\hline & & & 2.62 & 22.20 & قبلي & \\
\hline 0.982 & 0.001 & 39.531 & 1.91 & 55.10 & بعدي & التنميه البيئيه \\
\hline & & & 3.61 & 23.80 & قبلي & \\
\hline $0.9 / 8$ & 0.001 & 35.6 & 2.52 & 64.27 & بعدي & عتفدات البينئه \\
\hline & & & 2.56 & 36.87 & قبلي & الطابع الجمالى \\
\hline 0.974 & 0.001 & 32.34 & 2.68 & 67.80 & بعدي & \\
\hline 0900 & $00 \Omega 1$ & 51768 & 10.30 & 151.50 & قبلي & \\
\hline 0.990 & 0.001 & 51.108 & 11.50 & 357.84 & بعدي & \\
\hline
\end{tabular}

من الجدول السابق يتبين الآتي:

يوجد فروق ذات دلالة إحصائية بين متوسطي التطبيق القبلي والتطبيق البعدي لبعد

(حماية البيئة) أحد أبعاد مقياس الاتجاهات البيئية، حيث بلغت قيمة الدالالة (0.001) وهي لئي

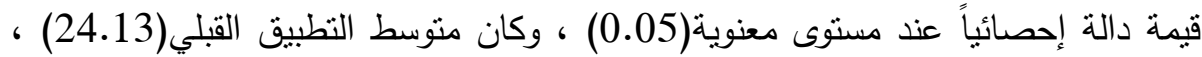
ومتوسط النطبيق البعدي(60.33) ، وبلغ حجم التأثير .(0.969)

يوجد فروق ذات دلالة إحصائية بين متوسطي التطبيق القبلي والتطبيق البعدي لبعد

(النمو السكاني) أحد أبعاد مقياس الاتجاهات البيئية، حيث بلغت قيمة الدلالة (0.001) وهي لئي

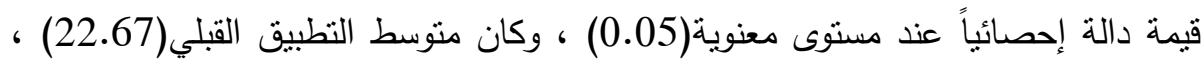

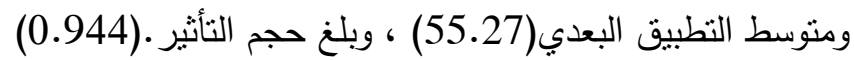


يوجد فروق ذات دلالة إحصائية بين منوسطي النطبيق القبلي والتطبيق البعدي لبعد

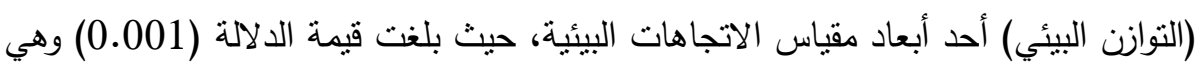

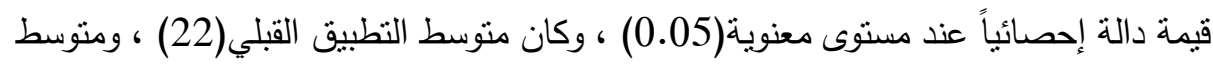
التطبيق البعدي(55.07) ، وبلغ حجم التأثنر . (0.982) يوجد فروق ذات دلالة إحصائية بين منوسطي التطبيق القبلي والتطبيق البعدي لبعد البداني

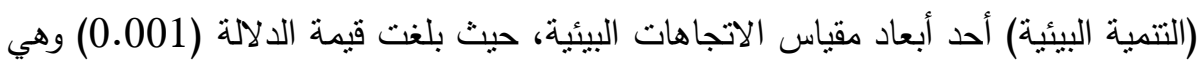
قيمة دالة إحصائياً عند مستوى معنوية(0.05) ، وكان متوسط التطبيق القبلي(22.20) ،

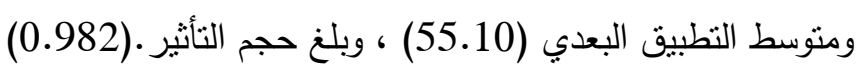
بينما لم يكن هناك فروق ذات دلالة إحصائية بين متوسطي التطبيق القبلي والتطبيق

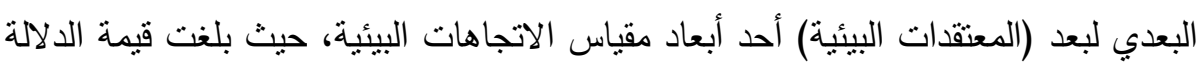

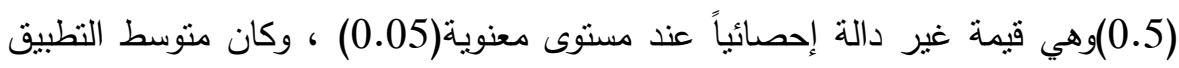

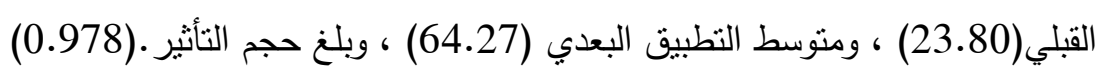
يوجد فروق ذات دلالة إحصائية بين منوسطي النطبيق القبلي والتطبيق البعدي لبعدي

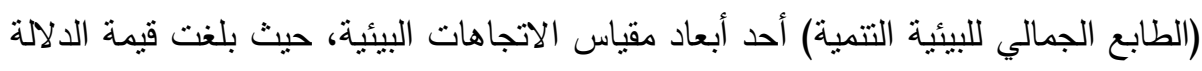

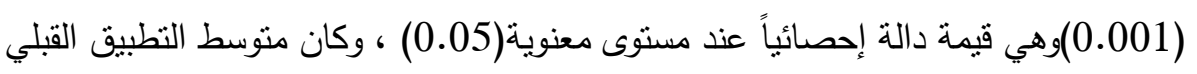

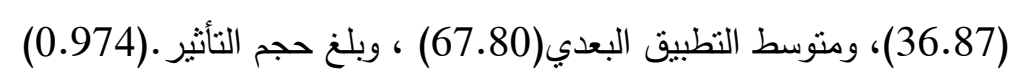

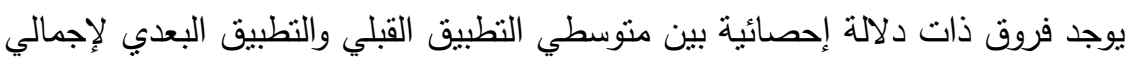

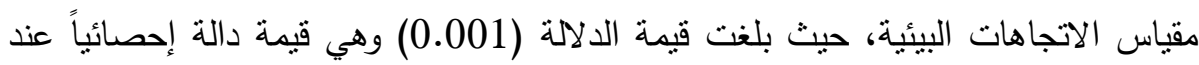
مستوى معنوية(0.05) ، وكان متوسط النطبيق القبلي(151.50) ، ومتوسط التطبيق البعدي

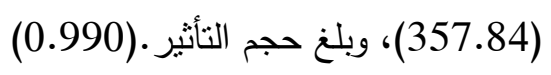


جدول رقم(ץ): اختبار ت T-Test (لتوضيح الفروق بين التطبيق القبلي والبعدي للمجموعة التجريبيةعشوائي)

\begin{tabular}{|c|c|c|c|c|c|c|}
\hline التأثُرٍ & المعنوية & قيمة ت & الألمعياري & المتوسط & المجموعة & أبعاد المقياس \\
\hline \multirow{2}{*}{0.886} & \multirow{2}{*}{0.001} & \multirow{2}{*}{14.774} & 0.77 & 38.80 & قبلي & \multirow{2}{*}{ حماية البيئة } \\
\hline & & & 4.03 & 54.47 & بعدي & \\
\hline \multirow{2}{*}{0.986} & \multirow{2}{*}{0.001} & \multirow{2}{*}{44.106} & 0.56 & 17.80 & قبلي & \multirow{2}{*}{ النمو السكاني } \\
\hline & & & 3.28 & 55.73 & بعدي & \\
\hline \multirow{2}{*}{0.976} & \multirow{2}{*}{0.001} & \multirow{2}{*}{33.708} & 0.56 & 26.80 & قبلي & \multirow{2}{*}{ التوازن البيئي } \\
\hline & & & 2.83 & 51.87 & بعدي & \\
\hline \multirow{2}{*}{0.976} & \multirow{2}{*}{0.001} & \multirow{2}{*}{33.708} & 0.56 & 26.85 & قبلي & \multirow{2}{*}{ التتمية البيئية } \\
\hline & & & 2.83 & 51.77 & بعدي & \\
\hline \multirow{2}{*}{0.979} & \multirow{2}{*}{0.001} & \multirow{2}{*}{36.352} & 0.35 & 23.13 & قبلي & \multirow{2}{*}{ المعتقدات البيئية } \\
\hline & & & 4.03 & 61.07 & بعدي & \\
\hline \multirow{2}{*}{0.950} & \multirow{2}{*}{0.001} & \multirow{2}{*}{23.015} & 0.62 & 40.33 & قبلي & \multirow{2}{*}{ للبيئية: الجمالى } \\
\hline & & & 3.50 & 61.47 & بعدي & \\
\hline \multirow{2}{*}{0.982} & \multirow{2}{*}{0.001} & \multirow{2}{*}{39.635} & 0.90 & 173.72 & قبلي & \multirow{2}{*}{ إجمالي المقياس } \\
\hline & & & 15.88 & 336.37 & بعدي & \\
\hline
\end{tabular}

من الجدول السابق يتبين الآتي:

يوجد فروق ذات دلالة إحصائية بين منوسطي التطبيق القبلي والتطبيق البعدي لبعد

(حماية البيئة) أحد أبعاد مقياس الاتجاهات البيئية، حيث بلغت قيمة دئية الدالالة (0.001) وهي

قيمة دالة إحصائياً عند مستوى معنوية(0.05) ، وكان منوسط التطبيق القبلي(38.80) ، ومتوسط النطبيق البعدي(54.47) ، وبلغ حجم التأثير . (0.886)

يوجد فروق ذات دلالة إحصائية بين متوسطي التطبيق القبلي والتطبيق البعدي لبعد

(النمو السكاني) أحد أبعاد مقياس الاتجاهات البيئية، حيث بلغت قيمة الدلالة (0.001) وهي ليكي

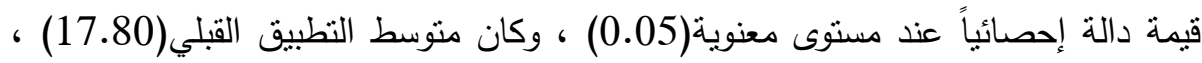
ومتوسط التطبيق البعدي(55.73) ، وبلغ حجم التأثير . (0.968)

يوجد فروق ذات دلالة إحصائية بين منوسطي التطبيق القبلي والتطبيق البعدي لبعد (التوازن البيئي) أحد أبعاد مقياس الاتجاهات البيئية، حيث بلغت قيمة الدلالة (0.001) وهي 
قيمة دالة إحصائياً عند مستوى معنوية(0.05) ، وكان متوسط التطبيق القبلي(26.80) ،

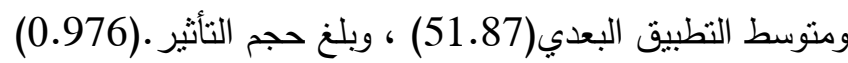
يوجد فروق ذات دلالة إحصائية بين منوسطي التطبيق القبلي والتطبيق البعدي لبعد

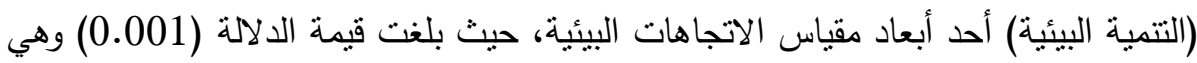
قيمة دالة إحصائياً عند مستوى معنوية(0.05) ، وكان متوسط التطبيق القبلي(26.80) ،

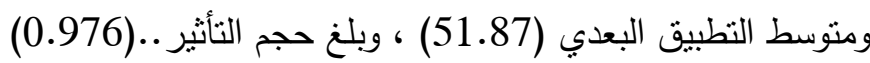
بينما لم يكن هناك فروق ذات دلالة إحصائية بين منوسطي التطبيق القبلي والتطبيق

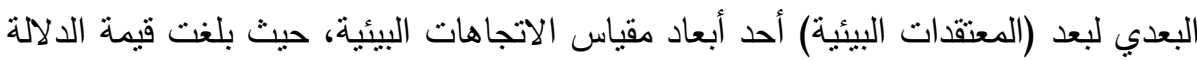

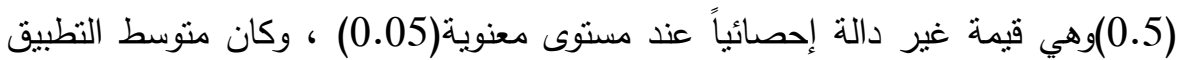

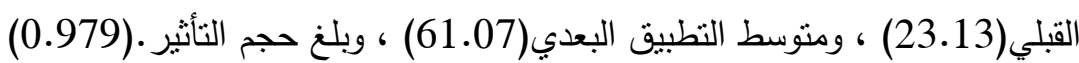
يوجد فروق ذات دلالة إحصائية بين منوسطي النطبيق القبلي والتطبيق البعدي لبعد البدابي

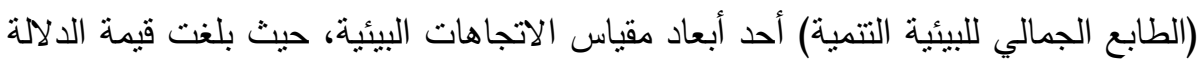
(0.001)وهي قيمة دالة إحصائياً عند مستوى معنوية(0.05) ، وكان منوسط التطبيق القبلي لئي

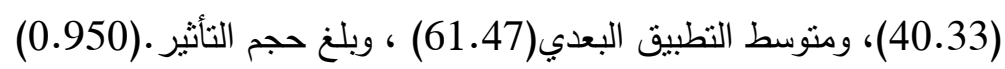
يوجد فروق ذات دلالة إحصائية بين منوسطي النطبيق القبلي والتطبيق البعدي لإجمالي

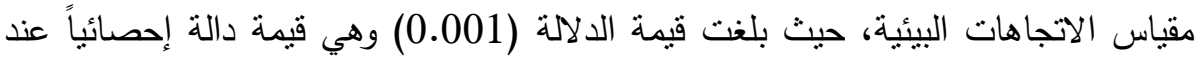
مستوى معنوية(0.05) ، وكان متوسط التطبيق القبلي(173.72) ، ومتوسط التطبيق البعدي

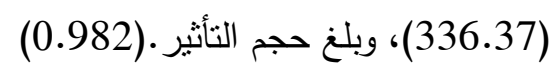
تفسير النتائج: 1- أثتتت نتائج الدراسة فاعلية تطبيق برنامج الششاركة السياسية فى تغير الاتجاهات البيئية

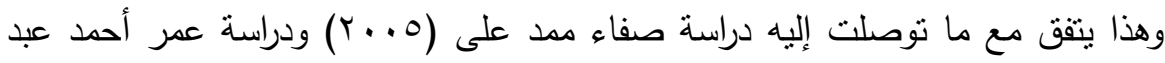

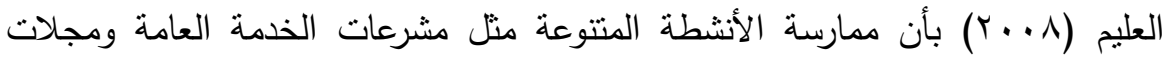

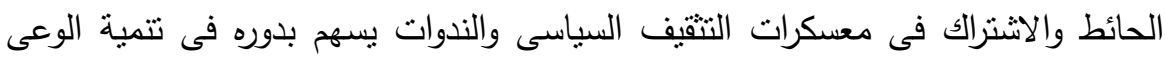
السياسى والذى دعم تغير الاتجاهات البيئية فى هذه الدراسة. وكذلك تتفق هذه النتيجة مع لئى 


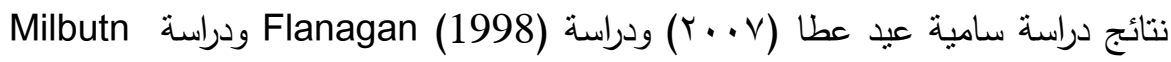
(2000) ودراسة (2009) Ckeckiway, berry فى الحاجة إلى عمل برنامج تدريبية فى المشاركة السياسية والتى من شأنها أن تساهم فى إيجاد اتجاهات جديدة نتموية تهنم بالجانب التطوعى وتدفعهم للمشاركة فى مناحى الحياة وتعزز سلوك الثباب الإيجابى تجاه

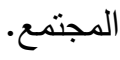

r-توجد فروق ذات دلالة احصائية بين العينات (عشوائى - حضرى) بإختلاف البيئات

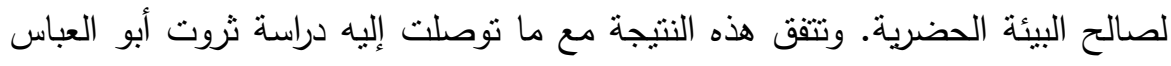
(Y. . V) بإختلاف نقافات وعادات وتقاليد كل بيئة ينمو فيها الفرد.

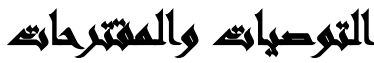

ا-نطبيق برنامج المشاركة السياسية على اعضاء مراكز الثباب من خلال التعامل بين مديريات الثباب فى المحافظات ووزارة الثباب. r-ضرورة تتفيذ معسكرات بيئية داخل وخارج مراكز الثباب لاكتساب مهارات بيئية والوعى البيئي.

r-ادراج برامج ضمن الخطة لنشئون مراكز الثباب تعمل على زيادة اعضاء المراكز وتعمل على زيادة الوعى السياسي لاعضاء المراكز (زيارات للاحزاب بالحي - زيارات لجمعيات

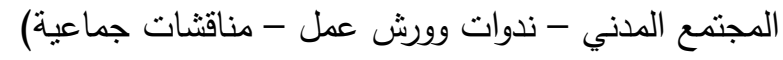

ع-تفعيل برلمانات الطلائع والثباب داخل مراكز الثباب وادراج برامج سياسية خاصة بهم ضمن خطة المراكز السنوية. ه-تدريب كوادر شبابية قادرة على أن تقوم بتدريب الطلائع والثباب على البرامج التتموية 


\section{المراليعة}

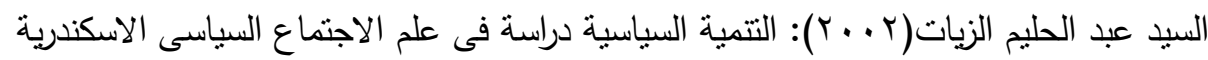

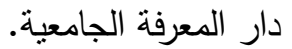

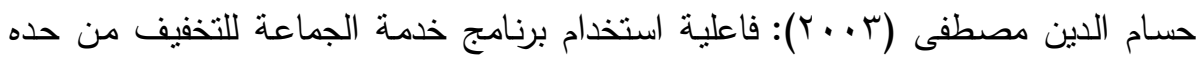

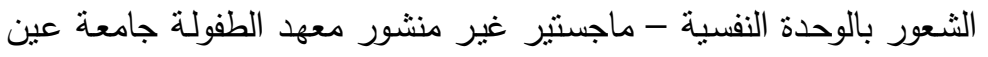

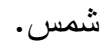

ثروت أبو العباس عثمان (V . . r): العلاقة بين بعض المشكلات الاجتماعية والنفسية والانتماء

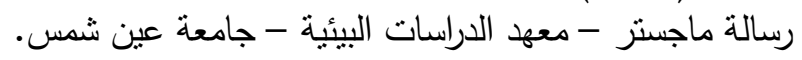

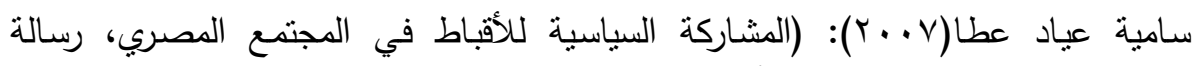
ماجستير ،كلية الآداب، جامعة عين شمس.

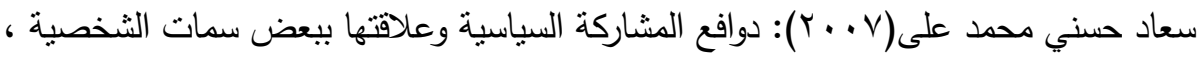

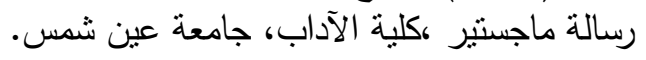

سلوى شعراوى جمعة(r + . r): السياسات الثبابية الامال والتطلعات تحت منشور القاهرة مركز دراسات واستشارات الادارة.

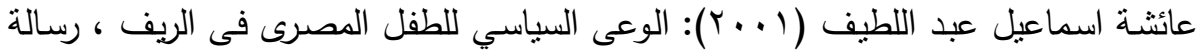

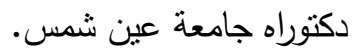

على الدين هلال(r . . r): (السياسات الثبابية الآمال والتطلعات ، مركز دراسات واسنشارات

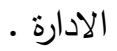

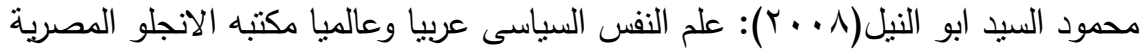

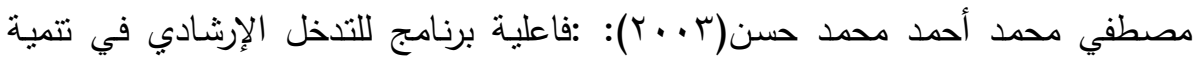

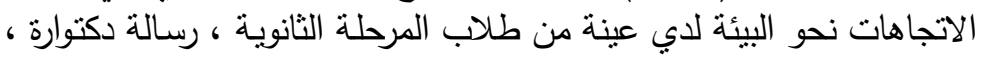

معهز الدراسات والبحوث البيئية.

Flanagan, Constance A: Sherrod, lonnice R:youth politicol development:Anintrod- uection (Journal of social / Issues. Vol 54 (3) fal 1998

Milburn, led: Connecting with young people and youth / Issues , Abstract of Journal Article youth policy, 200068 summery )

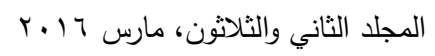


Paske, Josh : Kenski, kate: others : (America's youth and community Engagement: How use of Mass Media Is Related to Civic Activity and political Awareness in to 22 Year-Olds (Journal; peer Reviewed Journal Net: Vol 33 (3) Jun 2006).

Reinders, Hienz: Youniss , James : Community service and Political participation of American and German : Adolescents (Journal, peer Reviewed Journal) ( psycholigie in Eziehung und Unterricht. Vol 52(1) 2005. Net).

Richardson, wendy klandl: connecting politieal discussion to civic engagement: the role of e civic knowledge, offieacy and context for adolescents cdissertation Abstract International Section A : Humanities and social Scieness vol $64(9-\mathrm{A})$ 2004 


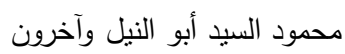

\title{
THE EFFECTIVENESS OF A PROPOSED PROGRAM FOR POLITICAL PARTICIPATION IN CHANGING THE ENVIRONMENTAL ATTITUDES AN EXPERIMENTAL STUDY ON A SAMPLE OF SOME OF CAIRO'S YOUTH CENTERS
}

\author{
Abou El-Neil, M. E. ${ }^{(1)}$; Helmy, Iglal, I. $^{(1)}$ and Ahmed, Th. A. O. ${ }^{(2)}$ \\ 1) Faculty of Arts, Ain Shams University, 2) Directorate of Youth and \\ Sports.
}

\begin{abstract}
This present study purpose is to design a program for political participation for increasing political awareness among youth which necessitates supporting change in environmental attitudes and checking efficacy of this program; From this major objective, there are minor objectives stated a follows: Working on assisting the experimental group to change attitude towards concerning in protection of the environment, population growth, environmental equilibrium, environmental development, and the aesthetic face.- of environment. It also drives at identifying the differences between the two experimental groups in their different samples (urban - rural) post application of the program. The researcher uses a number of instruments, using the experimental method for checking the efficacy of the program and for achieving study targets, namely, a program for political participation, Scale of Environmental attitudes. The study sample is consistent of a simple random sample of (60) male/female youth, divided equally into (30 males - 30 females). The study comes to these results: That the program of political participation has proved its efficacy in changing environmental attitudes. There are also significant statistical differences between the two study groups due to difference of environments (slum - urban) post application of the program on scale of environmental

$$
\text { المجلد الثاني والثلاثون، مارس } 17 \text {. }
$$


مجلة العلوم البيئية

معهد الدراسات والبحوث البيئية - جامعة عين شمس

attitudes, in favor of the experimental group in the urban area; while there are no significant statistical differences between males and females post application of the political participation program in both sample the slum as well as the urban. 